\title{
Health Status as a Correlate of Reading Comprehension Achievement in Senior Secondary Schools in Ebonyi State of Nigeria
}

\author{
Raphael I. Ngwoke, Ngozi Obeka, Fidelia A. Okonkwo \\ Department of Arts and Social Science Education, Faculty of Education Ebonyi State University, Abakaliki, Nigeria \\ Email: raphngwoke@gmail.com
}

How to cite this paper: Ngwoke, R.I., Obeka, N. and Okonkwo, F.A. (2019) Health Status as a Correlate of Reading Comprehension Achievement in Senior Secondary Schools in Ebonyi State of Nigeria. Open Journal of Social Sciences, 7, 411-419. https://doi.org/10.4236/jss.2019.712032

Received: November 11, 2019 Accepted: December 27, 2019

Published: December 30, 2019

Copyright $\odot 2019$ by author(s) and Scientific Research Publishing Inc. This work is licensed under the Creative Commons Attribution-NonCommercial International License (CC BY-NC 4.0).

http://creativecommons.org/licenses/by-nc/4.0/

\begin{abstract}
The study investigated health status as a correlate of reading comprehension achievement in Ebonyi State of Nigeria. A correlation design was adopted for the study. The population of the study was 33,986 and the sample size was 396 respondents selected, using the Taro Yamane sampling formulae. Instruments for data collection were a health status inventory and a reading comprehension text from the government prescribed text. One research question and one hypothesis were formulated for the study. While research question was answered using coefficient of correlation, hypothesis was tested at an alpha level of 0.05 of significance, using step-wise linear regression. Items whose " $T$ " was less than significance of " $T$ " were accepted, while items whose " $T$ " was more than significance of " $T$ " were rejected. Results showed that health status was a variable that has a high positive relationship with reading comprehension achievement. Result of hypothesis equally showed that " $\mathrm{T}$ " was greater than significance of " $\mathrm{T}$ " which was an indication that there is a significant relationship between health status and students' reading comprehension achievement. Based on this, recommendations were made, among which, is that the government of Ebonyi State should both approve and affect the setting up of health clinics in every secondary school of up to 1000 students and above, with at least one visiting doctor.
\end{abstract}

\section{Keywords}

Health Status, Reading Comprehension, Achievement, Senior Secondary School

\section{Introduction}

"Health is wealth" is a popular axiom which denotes the importance of healthy 
life in all human endeavors and achievement, including acquisition of good education. In terms of educational achievement, both mental stability and physical fitness play key roles in ensuring its attainment. Comprehension underpins every academic achievement since it is the only weapon at the disposal of a reader if he/she will utilize knowledge gained from a text, an observation or discussion.

The health status of students may have a correlation with their reading comprehension achievement and instructional delivery. Studies have shown that children who might have had pre-natal or post-natal malformation of the sensory organs as a result of mothers' health status and nutritional habits may have varying degrees of problems with reading comprehension exercises even in later academic performances. According to Tavano, Graso, Gagliardi, Triulzi, Bresolin, Fabro and Borgatti (2017) [1], "Cerebellar Cognitive Syndrome" which may manifest in a type of complex behavioural pattern in adults and children characterized by reduced cognitive efficiency could be a result of cerebral dysfunction resulting from a child's birth process. They went further to suggest that executive and visuospatial disorders which are a neuropsychological deficit, "mild agrammatism and anomia" which are seen in expressive language disorders all of which affect reading comprehension, could equally result from pre- or post natal maternal health dispositions or some delivery abnormalities.

According to World Health Organization (WHO) report (2019) [2], over 70\% of global deaths today are as a result of non-communicable diseases such as diabetes, cancer, heart diseases which often result from both environmental factors such as air pollution, tobacco and narcotic intakes. Mothers who are victims of such health-threatening circumstances often have the health of their babies affected which may manifest as neurological disorders. Disorder in the function of the nervous system can cause malfunction of the reasoning, and other sensory organs. Dyslexia or developmental reading disorder, for instance, has been mostly attributed to the malfunctioning of the nervous system. Brazier (2017) [3] posits that dyslexia as a disability which resides in the brain and can impair a victim's reading ability. According to Mayor Clinic (2017), the reading difficulty experienced by the dyslexic manifests in inability to identify speech sounds and to learn how such speech sounds relate to letters and words since the area of the brain affected is that which processes language. For that reason, despite having normal intelligence, the dyslexic victim is found reading at a glaringly lower level than is expected. The victim may equally not be able to have effective mind-eye co-ordination while reading. This disorder can occur as a genetic inheritance, or as a result of brain injury which could occur at birth or from a brain injury among adults. From Kitson's (2004) [4] analysis of the connections and workings of the brain, spinal cord and the mind or nervous system; it can be understood that when there is a brain disorder, the central nervous system is automatically in disorder and this can affect reading comprehension abilities of victims.

Apart from the brain-based reading problems, health challenges can be a factor in students' reading comprehension abilities. Students that often fall sick for 
long times easily lose out in such exercises like reading comprehension. Sickle cell victims for instance often encounter health crises and this may correlate with such children's academic achievement in reading comprehension. On the contrary, normal healthy students stand better chances of having better academic achievement, especially where there are available quality teachers.

Reading comprehension is a course of study that requires carefulness in both reasoning and use of language. If students' achievement in this subject vis-à-vis English language will witness improvement, the students who will be tested need to be in good health mentally and physically. According to Kidshealth.org (2016) [5], the brain is like a computer that controls the body functions. A student with dyslexia will have difficulty doing an independent academic study; he is also deficient in comprehension that proves reading effectiveness. Dyslexia and intelligence Quotient (IQ) do not have relationship since reading develops independently from cognition in dyslexic victims.

Hyperlexia is another type of brain-related health status that can impede reading comprehension achievement of learners. Hyperlexia can be seen as a disability in ability where the victim actually has an average or above-average intelligence quotient (IQ) and word-reading ability well above what would be expected at their age and IQ. Treffert (2016) [6] identifies three types of hyperlexia. According to Treffert, hyperlexia type 1 manifest in ordinary or neuro-typical children reading very early in life more than is normal. Type 2 occurs in children in the autistic spectrum and, in such circumstance, they are usually obsessed with arranging letters and numbers endlessly, taking magnetic tablets to bed rather than toys or stuffed animals, while type 3 manifests in children that read very early and occasionally showing autistic signs, having impressive memories for music or movies, having pronounced reading comprehension ability yet with delayed verbal language over time. Bainbridge (2016) [7] states that hyperlexic children read at levels far beyond those of their age mates and often begin reading at very young ages. Brainbridge maintains that hyperlexic children don't learn language in the typical language learning progression of sound-words: sentences, nor do they begin to develop a vocabulary starting with nouns. However, hyperlexic children often exhibit echolalia, which is a repetition of phrases and sentences without understanding the meaning. Word recognition ability of hypelexics goes beyond expected levels of skill, yet they have difficulty understanding speech. But where comprehension of a reading text is lacking, reading becomes a wasted exercise.

Reading and comprehension are twin concepts bound by a common chain since no meaningful reading can be said to have taken place where the reader fails to comprehend what has been read. No matter how intelligent a reader may be, if there is no comprehension of reading texts, that reader is bound to have a poor achievement in public examinations.

When the brain is affected by some internal or external forces, reading with comprehension becomes defective. An emotional upset due to information re- 
ceived by the learner, a psychological depression resulting from some maltreatment or an accident involving any part of the body is capable of stalling effective reading comprehension among students. In describing the interconnectivity of brain with the rest part of the human body, Kitson (2004) [4] maintains that at the base of the brain is located the spinal cord, which is a long strand of nerve fibers which extends down the spinal cord. The brain and spinal cord, with all its ramifications constitute the nervous system. This means that the brain is connected with the central nervous system. Mandal (2016) [8] describes the nervous system as a complex network of nerves and cells that carry messages to and from the brain and spinal cord to various parts of the body. Each time anything occurs in the mind, there is a change in some point of the nervous system. When applied to reading comprehension, it becomes quite obvious according to Kitson that when one is reading, memorizing vocabularies, making arithmetical calculations, and reasoning out problems in geometry, one is making changes in one's nervous system. The action of the nervous system is best conceived as a form of chemical change that spreads among the nerve cells. As a result of this connectivity, any negative information or treatment received by the learner, goes to destabilize the entire body system, misbalances the mind and so impedes comprehension. This study examined the correlation between health status and senior secondary school students' reading comprehension achievement in Ebonyi State of Nigeria.

\subsection{Statement of the Problem}

The overall achievement of candidates in the Senior Secondary School Certificate examination in English has left much to be desired. Results so far obtained from West African Examination Council [9] have continued to show a fluctuation in performance for the past five years. Between 2015 and 2019, percentage scores of candidates who scored up to 5 credits and above in English and Mathematics stand at $39.00 \%, 53.19 \%, 54.06 \%, 49.98 \%$, and $64.18 \%$ respectively. Reading Comprehension is an integral aspect of the English language study which prepares students for effective writing and in-depth reasoning and for that, it usually attracts a great chunk of the marks in the examination. It therefore implies that a poor achievement in reading comprehension will correlate with a poor achievement in English as a whole. The health status of the students in school may equally correlate with achievement in the qualifying examination. It is feared that if the problems are not identified and treated, achievement in English in the Senior Secondary School Certificate Examination may remain on its current fluctuating and unpredictable state. The problem of this study is to identify the relationship between health status and senior secondary school students' achievement in English in Ebonyi State.

\subsection{Purpose of the Study}

The main purpose of this study was to identify the relationship between health 
status and senior secondary school students' achievement in English in Ebonyi State.

\subsection{Research Question}

One research question was formulated to guide the study as follows: What is the relationship between health status and senior secondary school students' achievement in reading comprehension in English in Ebonyi State?

Hypothesis: One null hypothesis was tested at 0.05 level of significance thus:

There is no significant relationship between health status of senior secondary school students' achievement in reading comprehension in English in Ebonyi State of Nigeria.

\section{Methodology}

The design adopted for this study was a correlation design. Health status was correlated with students' achievement in reading comprehension. A correlation study according to Cheprasov (2018) [10], is that used by the researcher to investigate relationships that naturally exist among variables and in what way.

The population for this study consisted of all SS2 students in the 189 public senior secondary schools in the three Education Zones in Ebonyi State, whose population was 33,986 .

In the three Education Zones, all the senior secondary schools study English language and also use the same recommended text books in English. Using Taro Yamane formula for determining sample size, a sample size of 396 respondents was selected from the student population. Yamane's formula runs thus:

$$
n=N /\left(1+N e^{2}\right) \text {. }
$$

where $n=$ sample size;

$N=$ population under study; $=33,986$.

$e=$ margin of tolerable error; $=0.05$.

$n=\frac{33,986}{1+33,986(0.05) 2}=395.3469 \approx 396$

Using simple random sampling by balloting, 20 senior secondary schools were selected representing $34 \%$. Randomization ensured urban and rural coverage.

The instruments for data collection were: (i) a reading comprehension test adapted from the prescribed English text for senior school classes-Intensive English for Senior Secondary Schools 2, and a Health Status Inventory (HSI) designed by the researcher. The Health Status inventory sought to reveal certain health conditions of learners that impeded their active participation in and comprehension of a reading comprehension text. Such conditions as a head injury that affected the brain, distraction by background noise, occasional memory loss, among others, were investigated by the inventory.

The researcher used a total of six (6) research assistants who were teachers, to administer both the questionnaire and the comprehension passage. The research 
assistants supervised the students after instructing them on what they were required to do in each of the instruments. Their supervisory role ensured the students worked independently. The reading comprehension passage test was collected and later marked and scored based on $100 \%$. The HSI, which was administered the next day to the same group of respondents, was equally collected on the spot ensuring that no instrument was lost, and so there was a $100 \%$ return.

The instruments which consisted of the Reading Comprehension test (RCT) and Students' Health Status Inventory (SHSI) were administered to a group of thirty five (35) students of SS2 classes from Okpuitumo Secondary School, Ikwo in Ikwo Local Government Area of Ebonyi State, who were not part of the sampled population for the main study. This was a trial testing. The Reading Comprehension Test (RCT) was subjected to a six man judges' rating on six students. The rankings from the judges were used in Kendal Coefficient of Concordance (KCC) which yielded a reliability coefficient of 0.84 which showed that the instrument was suitable for use. The Students' Health Status Inventory which had thirty items was also administered to thirty five (35) respondents. Data collected were used to compute the reliability coefficient based on Crombac Alpha. The reliabilities of the instrument based on clusters $1,2,3$ were $0.87 ; 0.81$; and 0.76 . However, the reliability for the entire instrument of thirty (30) items was 0.91 which showed a high internal consistency, and therefore suitable for the study.

While Research question was answered using coefficient of correlation, hypothesis was tested at an alpha level of 0.05 of significance, using step-wise linear regression. Items whose "T-calculated" were less than significance of " $\mathrm{T}$ " were accepted, while items whose "T-calculated" were greater than significance of "T" were rejected. The correlation coefficient table as proposed by Nwana (2008) [11] was used as bench mark for interpreting the degree of relationship. According to Nwana (2008:311) the correlation interpretation Table 1 runs thus:

\section{Results}

\section{Research Question}

What is the relationship between health status and senior secondary school students' achievement in reading comprehension in English in Ebonyi State?

In Table 2, the relationship between health status and Reading Comprehension Achievement was 0.72. This falls within $0.60-0.80$ and showed a high and positive relationship. This shows there is a relationship between health status and students' reading comprehension achievement.

Ho: There is no significant relationship between students' health status and senior secondary school students' achievement in reading comprehension in English in Ebonyi State.

Result in Table 3 indicated that "T-cal" which is 20.873 was greater than significance of " $T$ ". The hypothesis was therefore rejected. It means there is significant relationship between students' health status and their achievement in reading comprehension. 
Table 1. Table of interpretation of correlation coefficient.

\begin{tabular}{ll}
\hline Correlation & \multicolumn{1}{c}{ Interpretation } \\
\hline 0.80 to 1.00 & Very High, Near perfect Relationship \\
0.60 to 0.80 & High Relationship \\
0.40 to 0.60 & Medium Relationship \\
0.20 to 0.40 & Low, Definite Positive Relationship \\
0.00 to 0.20 & Very Low, Virtually No Relationship \\
\hline
\end{tabular}

Table 2. Correlation coefficient between health status and achievement.

\begin{tabular}{ccc}
\hline Variables & Achievement & Health Status \\
\hline \multirow{3}{*}{ Achievement } & 1.0000 & 0.7246 \\
& $(396)$ & $(396)$ \\
& $\mathrm{P}=0.000$ & $\mathrm{P}=0.000$ \\
& 0.7246 & 1.0000 \\
Health Status & $(396)$ & $(396)$ \\
& $\mathrm{P}=0.000$ & $\mathrm{P}=0.000$ \\
\hline
\end{tabular}

$$
\mathrm{r}=0.72
$$

Table 3. Significances of relationship between students' health status and reading comprehension achievement.

\begin{tabular}{cccccccc}
\hline Variable & Computed R & R-Squared & Adjusted R-Squared & Standard Error & Beta & “T” & Significance of “T” \\
\hline Health Status & 0.7246 & 0.5251 & 0.5239 & 7.5959 & 0.7246 & 20.873 & 0.0000 \\
Constant & & & & & 3.527 & 0.0005 \\
\hline
\end{tabular}

Significant at $\mathrm{P}<0.05$.

\section{Discussion}

\section{Relationship between Health Status and Senior Secondary School Students' Reading Comprehension Achievement}

With a correlation coefficient of 0.72 , result showed a high relationship between health status and, senior secondary school students' reading comprehension achievement. There was equally a corresponding result in the corresponding hypothesis. Result of hypothesis indicated that 'T-cal' was 20.87 which was higher than significance of "T". The hypothesis was rejected since it showed that there was a significant relationship between health status and senior secondary school students' reading comprehension achievement. An unhealthy student cannot function positively in a learning situation as that student is academically "unhealthy".

Result showed that health status was a variable that had a significant relationship with achievement. This agrees with Stanovich (1988) [12] and Kitson (2004) [4] who maintain that there is interconnectivity of the brain and the nervous system and suggest that a brain disorder will automatically disorganize the central nervous system thus causing a reading comprehension defect. When there is disorder in the brain or in the function of the body system, learning and comprehension are affected negatively. 


\section{Conclusion}

Having established that there is a strong correlation between health status and students' reading comprehension achievement in school, through such carefully conducted investigation, it is therefore safe to conclude that both government and private efforts of individuals and non-governmental agencies are needed to equip schools with adequate health facilities and appropriate health personnel to provide both remedial and preventive health care and appropriate health personnel in schools and for schools in Nigeria.

\section{Limitations to the Study}

One of the limitations of this study was the uncooperative attitude of some English language teachers in releasing their classes for use in conducting the reading comprehension achievement tests. Some teachers viewed the request to use their students as undue interference to their normal class teachings. This attitude further lengthened the duration of the collection of data as dates continued to change.

On the part of students, the realization at a point that the test was not going to be part of their terminal achievement scores, created apathy in most of them leading to the dropping of such classes and replacing them with more 'serious' classes.

\section{Recommendation}

Government should approve and effect the opening of health clinics in every secondary school in the state. Such clinics should have at least one consulting doctor and two nurses for a school population of up to 1000, who must be paid by government. While the nurses run regular clinical services all through the week, consulting doctors should be available for periods not less than three days per week for day schools and up to four days for boarding schools.

Since brain-based problems can lead to reading comprehension disability which often leads to low achievement, and since it may not be financially feasible for government to maintain many doctors of various fields of specialization in schools at the same time, government should consider linking up secondary schools with government-owned hospitals so that any problem which the school clinics cannot handle is swiftly transferred to hospitals without undue protocol that might bring about delays that might put such life in danger.

Professionally trained education counselors should be posted to secondary schools by government to take up guidance of students on vocational choices, study habits as well as the psychological and emotional dispositions that often impact on academic learning. There should be at least two of such counselors for a school population of up to one thousand (1000) students. A student who is psychologically depressed and emotionally unbalanced will hardly achieve much in academic tasks. 


\section{Conflicts of Interest}

The authors declare no conflicts of interest regarding the publication of this paper.

\section{References}

[1] Tavano, A., Graso, R., Gagliardi, C., Triulzi, F., Bresolin, N., Fabro, F. and Borgatti, R. (2017) Disorders of Cognitive and Affective Development in Crebellar Malfunctions. Journal of Neurology, 130, 2640-2660.

[2] World Health Organizatio (2019) Ten Threats to Global Health. https://www.who.int

[3] Brazier, Y. (2017) What You Need to Know about Dyslexia. Medical News Today. https://www.medicalnewstoday.com

[4] Kitson, H.D. (2004) How to Use Your Mind. http://www.gutternberg.net/

[5] Kidshealth.org (2016) Brain and Nervous System. http://www.kidshealth.org

[6] Treffert, D.M.D. (2016) Hyperlexia in Children: What Is It and What to Look for? https://www.agnesian.com

[7] Bainbridge, C. (2016). Description of Hyperlexia. https://www.verywell.com

[8] Mandal, A.M.D. (2016) What Is the Nervous System? http://www.newsmandal.net

[9] West African Examination Council (2018) May/June 2018 Result Analysis Breakdown and Statistics. https://www.mypastquestion.cocm

[10] Cheprasov, A. (2018) What Is a Correlational Study? https://www.study.com

[11] Nwana, O.C. (2008) Introduction to Educational Research. HEBN Publishers PLC, Ibadan.

[12] Stanovic, K.E. (1988) Explaining the Difference between the Dyslexic and the Garden-Variety Poor Reader. Journal of Learning Disabilities, 130, 2640-2660. 